This is an open access article under the CC BY-NC-ND license (https://creativecommons.org/licenses/by-nc-nd/3.0/) Issue III, November 2020

ISSN 2707-9481

ISBN 978-601-323-207-2

https://doi.org/10.31643/2020.019

\author{
N. A. Bondarenko \\ Kuban state University, Russia \\ I. V. Ivanus \\ E-mail:rgm@kubsu.ru \\ Kuban state University, Russia \\ E-mail:rgm@kubsu.ru \\ ORCID ID: https://orcid.org/0000-0002-3949-4074 \\ ORCID ID: https://orcid.org/0000-0002-1557-8302 \\ T. N. Kuropatkina \\ Kuban state University, Russia \\ E-mail:rgm@kubsu.ru \\ ORCID ID: https://orcid.org/0000-0002-6993-9062 \\ A. A. Zolotarev \\ AO SevKavTISIZ, Russia \\ E-mail: mail@sktisiz.ru \\ ORCID ID: https://orcid.org/0000-0003-3248-8234
}

\title{
Assessment of terrain as a factor in the development of erosion processes based on GIS technologies
}

\begin{abstract}
We analyzed: 1) morphometric characteristics of the terrain: density of dissection $(\mathrm{km} / \mathrm{km} 2)$, depth of dissection $(\mathrm{m} / \mathrm{km} 2)$, General dissection of the terrain $(\mathrm{km} / \mathrm{km} 2)$, obtained by multi-stage processing of data from The earth's radar survey (SRTM). Overlay analysis of the following maps was performed: maps of the density of the terrain division, maps of the depth of the terrain division, and maps of the General terrain division. A geo-information model of potentially dangerous areas of origin and development of erosion processes was created based on the overlay of zones of the highest values of terrain dissection. The resulting map was created by interpreting the results of overlay operations and defining extreme values for each parameter. The graphic constructions obtained from a set of morphometric indicators will be of great applied value when planning the construction of new socio-economic objects, when developing General schemes for expanding existing settlements and designing new ones, when planning the construction of linear objects, as well as when developing measures for the engineering protection of territories, buildings and structures.
\end{abstract}

Keywords: morphometry, erosion processes, terrain dissection, overlay analysis of factors.

Cite this article as: Bondarenko N. A., Ivanus I. V., Kuropatkina T. N., Zolotarev A. A. (2020). Otsenka rel'yefa kak faktora razvitiya erozionnykh protsessov na osnove GIS-tekhnologiy [Assessment of terrain as a factor in the development of erosion processes based on GIS technologies]. Challenges of Science. Issue III, p.: 137-144. https://doi.org/10.31643/2020.019

\section{Н.А. Бондаренко}

Кубанский государственный университет, Россия

E-mail: rgm@kubsu.ru

ORCID ID: https://orcid.org/0000-0002-3949-4074

Т.Н. Куропаткина

Кубанский государственный университет, Россия E-mail: rgm@kubsu.ru

ORCID ID: https://orcid.org/0000-0002-6993-9062
И.В. Иванусь

Кубанский государственный университет, Россия. E-mail: rgm@kubsu.ru

ORCID ID: https://orcid.org/0000-0002-1557-8302

А.А. Золотарев

АО СевКавТИСИЗ, Россия

E-mail: mail@sktisiz.ru

ORCID ID: https://orcid.org/0000-0003-3248-8234

\section{Оценка рельефа как фактора развития эрозионных процессов на основе ГИС-технологий}

\footnotetext{
Абстракт. Были проанализированы: 1) морфометрические характеристики рельефа: густота расчленения $\left(\kappa м / \mathrm{k}^{2}\right)$, глубина расчленения $\left(\mathrm{м} / \mathrm{\kappa M}^{2}\right)$, общее расчленение рельефа (км/км $\left.{ }^{2}\right)$, полученные путем
} 
многоступенчатой обработки данных радиолокационной радарной съемки Земли (SRTM). Осуществлен оверлейный анализ следующих карт: карты густоты расчленения рельефа, карты глубины расчленения рельефа и карты общего расчленения рельефа. На основании наложения зон наиболее высоких значений расчлененности рельефа была создана геоинформационная модель потенциально-опасных участков зарождения и развития эрозионных процессов. Создание результирующей карты выполнялось путем интерпретации результатов оверлейных операций и определения экстремальных значений по каждому параметру. Полученные по комплексу морфометрических показателей графические построения будут иметь большое прикладное значение при планировании строительства новых социально-экономических объектов, при разработке генеральных схем расширения существующих населенных пунктов и проектировании новых, планировании строительства линейных объектов, а также при разработке мероприятий инженерной защиты территорий, зданий и сооружений.

Ключевые слова: морфометрия, эрозионные процессы, расчленение рельефа, оверлейный анализ факторов

Введение. Освоение территории Северо-Западного Кавказа рассматривается как одно из приоритетных направлений в развития курортной отрасли юга России. На фоне сложного инженерногеологического строения данной территории, важная роль здесь принадлежит вопросам изучения особенностей рельефа, поскольку рельеф оказывает большое влияние на устойчивое развитие территории (расположение производств, дорожно-транспортная инфраструктура, строительство).

Как и гидросферный фактор рельеф является одним из ведущих показателей при оценке условий формирования и развития опасных экзогенных геологических процессов. От степени их изученности зависит обоснованность решений по инженерной подготовке территорий населенных пунктов, в т.ч. по инженерной защите объектов инфраструктуры от последствий паводковых, поверхностных вод и других катастрофических явлений.

При рассмотрении изменений среднегодовых сумм осадков на территории Краснодарского края за более чем 70-летний период можно отметить, что увеличение количества осадков отмечается с 1960 г. по настоящее время. Наиболее влажными за рассматриваемый период наблюдений были 1987 г., 1988 г., 1992 г., 1997-1999 гг., 2004 г., 2005 г., когда среднегодовое количество осадков составляло 138-148 \% нормы (Ткаченко, 2015). Больше всего осадков выпадает на южном склоне СевероЗападного Кавказа, где среднегодовое их значение составляет (в мм): Ачишхо - 3200, Красная Поляна — 1676, Сочи — 1500, Туапсе — 1424. К северо-западу от Туапсе их количество уменьшается и составляет в Джубге 1176, Геленджике - 779, Новороссийске - 805, Анапе - 533.

В последние 10 лет повторяемость сильных дождей (не менее 50 мм за период не более чем за 12 часов или 30 мм за час и менее) возросла. Имеется явно выраженный положительный тренд числа опасных явлений (ОЯ) и неблагоприятных гидрометеорологических явлений (НГЯ), которые наносят экономический ущерб горным территориям Краснодарского края. Так по данным Гидрометеорологического бюро муниципальных образований (МО) зафиксированы - 17 июня 2005 г. в Туапсинском районе (метеостанция Горный) в течение суток выпало 296 мм осадков, 6-7 июля 2012 г. в районе Геленджика и Новороссийска выпало больше 300 мм (311 мм Геленджик), 24 октября 2018 г. в Туапсинском районе количество осадков составило 215 мм, из них в период с 06.00 до 18.00 выпало 152 мм, в период с 12.40 до 13.40 выпало 63 мм ${ }^{1 .}$ По данным метеостанции Горный в период с 18.00 до 23.00 выпало 57 мм осадков, наблюдался очень сильный дождь. По данным гидрометеорологического поста г. Хадыженске (МО Апшеронский район) в период с 08.00 до 20.00

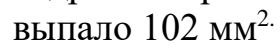

Самые катастрофичные стоковые наводнения были в 1991 (Сочинский и Туапсинский р-ны), 2002 (Сочинский и Новороссийский р-н), 2010 (Туапсинский р-н) и 2012 гг. (Геленджикский и Туапсинский р-ны). Ущерб от наводнений в августе 1991 г. оценили примерно в 230-345 млн долл., число жертв составило 27 чел.; в августе 2002 г. — в 58,2 млн долл. и 59 чел.; в октябре 2010 г. — в 30-90 млн долл. и 17 чел.; в августе 2012 г. — в 33 млн долл. и 4 чел. (по Туапсинскому р-ну) ${ }^{3 .}$

\footnotetext{
1 Официальный сайт органов местного самоуправления муниципального образования Апшеронский район. Электронный pecypc: http://www.apsheronsk-oms.ru (дата обращения 15.09.2020)

2 Официальный интернет-портал администрации муниципального образования Туапсинский район. Электронный pecypc: https://tuapseregion.ru/region/ (дата обращения 16.03.2020)

${ }^{3}$ Паспорт гидрометеорологической безопасности Краснодарского края. Обнинск, 2017. 117 с.
} 
Анализ повторяемости суммарного количества ОЯ, осредненных по территории МО Краснодарского края показывает, что наибольшая повторяемость опасных явлений погоды наблюдается на северном и южном склонах Северо-Западного Кавказа, с максимумом в Геленджикском районе (Васильев, 2017).

Известно, что южный склон Северо-Западного Кавказа относится к территории с сильной и очень сильной водной эрозией, а северный склон - к очень сильной водной эрозии и потенциально предрасположенной к очень сильной водной эрозии. Однако имеющийся масштаб графических построений не позволяет детализировать особенности строения территории и применить эти данные для градостроительной деятельности, производства инженерных изысканий и проектирования. В связи с этим возникает необходимость проведения среднемасштабных инженерно-геологических исследований с целью выявления потенциально-опасных участков зарождения и развития эрозионных процессов в пределах горных территорий.

Для создания карт факторов, влияющих на возникновение или развитие опасных геологических процессов, могут быть использованы любые автоматизированные системы: САПР, mapping системы, но наиболее эффективным инструментом для этого служат геоинформационные системы. На сегодняшний день существует много программных продуктов зарубежного и отечественного производства, позволяющих создавать ГИС-проекты различного содержания (ArcGIS, ГИС MapInfo Professional, ActiveMap GS, ГИС «ИнГЕО» и др.).

Анализ рельефа с применением ГИС-технологий успешно используется для решения вопросов экологии, ландшафтоведения, нефтегазовой отрасли, имеется опыт и для территории Краснодарского края (Буряк, 2014; Золотарев, 2018; Ермолаев и др., 2019; Бондаренко и др., 2020). Однако с такой целью и степенью детальности для территории Северо-Западного Кавказа морфометрический анализ на базе ГИС-технологий проводиться впервые, что подчеркивает актуальность работы - получение количественной информации как источника для последующей организации рельефа при составлении генпланов для застройки и освоения территорий. Полученные в ходе такого анализа данные способствуют функциональному зонированию территории и определению основных мероприятий по ее устойчивому развитию.

Материалы и методы исследования. Исследования проводились на территории муниципальных образований Апшеронский и Туапсинский районы Краснодарского края в наиболее хозяйственно освоенной их части. Площадь исследования составила 1012,87 км².

По климатическому районированию здесь выделяются две зоны: район ІІІ Б (северный склон) и IV Б (южный склон) ${ }^{4}$. Суммы осадков год от года могут значительно отклоняться от среднего значения. Так среднегодовое количество осадков северного склона по м.ст. Горный 1782 мм. В тёплый период года, с апреля по октябрь, выпадает 855 мм осадков (48 \% от годового количества осадков), в холодный, с ноября по март - 927 мм (52 \%). Среднегодовое количество осадков для южного склона по м.ст. Туапсе 1416 мм. В тёплый период года, с апреля по октябрь, выпадает 707 мм осадков (49,9 \% от годового количества осадков), в холодный, с ноября по март - 709 мм $(50,1 \%)^{5}$.

Основной объем исследований проводился с использованием метода картографического анализа, который осуществлялся в геоинформационной системе ArcGIS, приложение ArcMap. B работе в качестве исходных данных для получения информации о строении рельефа использовались материалы общедоступной радиолокационной топографической съемки Земли - shuttle radar topography mission (SRTM). Оценка рельефа проводилась для более объективной характеристики и сравнительно-картографического анализа определенных участков, установления роли того или иного вида расчлененности рельефа в развитии процессов эрозии, а также для выявления участков с разным потенциалом рельефа для развития опасных геологических процессов. Для рассматриваемой территории был осуществлен оверлейный анализ следующих карт морфометрических показателей: карты густоты расчленения (горизонтальное расчленение) рельефа, карты глубины расчленения рельефа (вертикальное расчленение) и карты общего расчленения рельефа. Отдельно показатели расчлененности дополнены картами углов наклона земной поверхности и экспозиции склонов.

Результаты исследования и их обсуждение. Составленная по результатам оценки густоты расчленения рельефа карта (рис. 1) обнаружила, что этот показатель изменяется от 0,5 до 6,6 км/км². Используя данные SRTM, в векторный линейный слой извлекались постоянные и временные водотоки. Затем рассчитывалась в пределах каждого квадрата их протяженность. Показателями

\footnotetext{
${ }^{4}$ СП 131.13330.2018 Строительная климатология

${ }^{5}$ Научно-прикладной справочник «Климат России». Электронный pecypc: http://aisori.meteo.ru/ClspR (дата обращения 20.04.2019)
} 
интенсивности служит: длина тальвегов эрозионных форм на единицу площади. Анализ эрозионной сети показал, что наибольших значений показатель интенсивности достигает в долине р. Пшиш, Туапсе, Гунайка, М. Псеушхо. Карта глубины эрозионного расчленения приведена на рис. 2. Наименьшая глубина расчленения фиксируется в центральной части территории, которая в тектоническом отношении относится к Гойтхско-Ачишхинской складчатой зоне и характеризуется наибольшей прочностью горных пород. Карты густоты и глубины расчленения в совокупности дают очень полное и наглядное представление о морфометрии рельефа. Тем не менее, на следующем этапе была построена карта общего расчленения рельефа, представленная на рис. 3. Из растра рельефа SRTM в векторный линейный слой извлекались горизонтали. Результирующий слой представляет собой сумму длин всех горизонталей в пределах единицы площади. Из анализа карты следует, что чем выше значение данного показателя, тем рельеф менее однородный - может включать в себя несколько геоморфологических элементов и характеризуется изменчивостью по латерали.

Каждая из построенных карт была классифицирована на 7 классов в автоматическом режиме способом «квантиль» - диапазон значений разбивался на неравные интервалы, но в каждом интервале содержалось одинаковое число значений, что делает выделенные интервалы равнозначными. В дальнейшем применено округление значений до одного знака после запятой. На основании этой классификации определены граничные значения, превышение которых принимается как наиболее высокие значения расчлененности.

Для территории исследований наиболее высокие показатели составляют:

- густота расчленения $>3,5$ км/км²;

- глубина расчленения $>350 \mathrm{~m} / \mathrm{\kappa M}^{2}$;

- общее расчленение $>55$ км/км².

Зоны ранжировались по категориям по следующим принципам:

1-я зона - высокие значения густоты расчленения без пересечения с другими максимальными показателями,

2-я зона - территории с высокой густой расчленения в местах пересечения с зонами высокой глубины расчленения;

3-я зона - области пересечения максимальных показателей по 3-м показателям расчлененности.

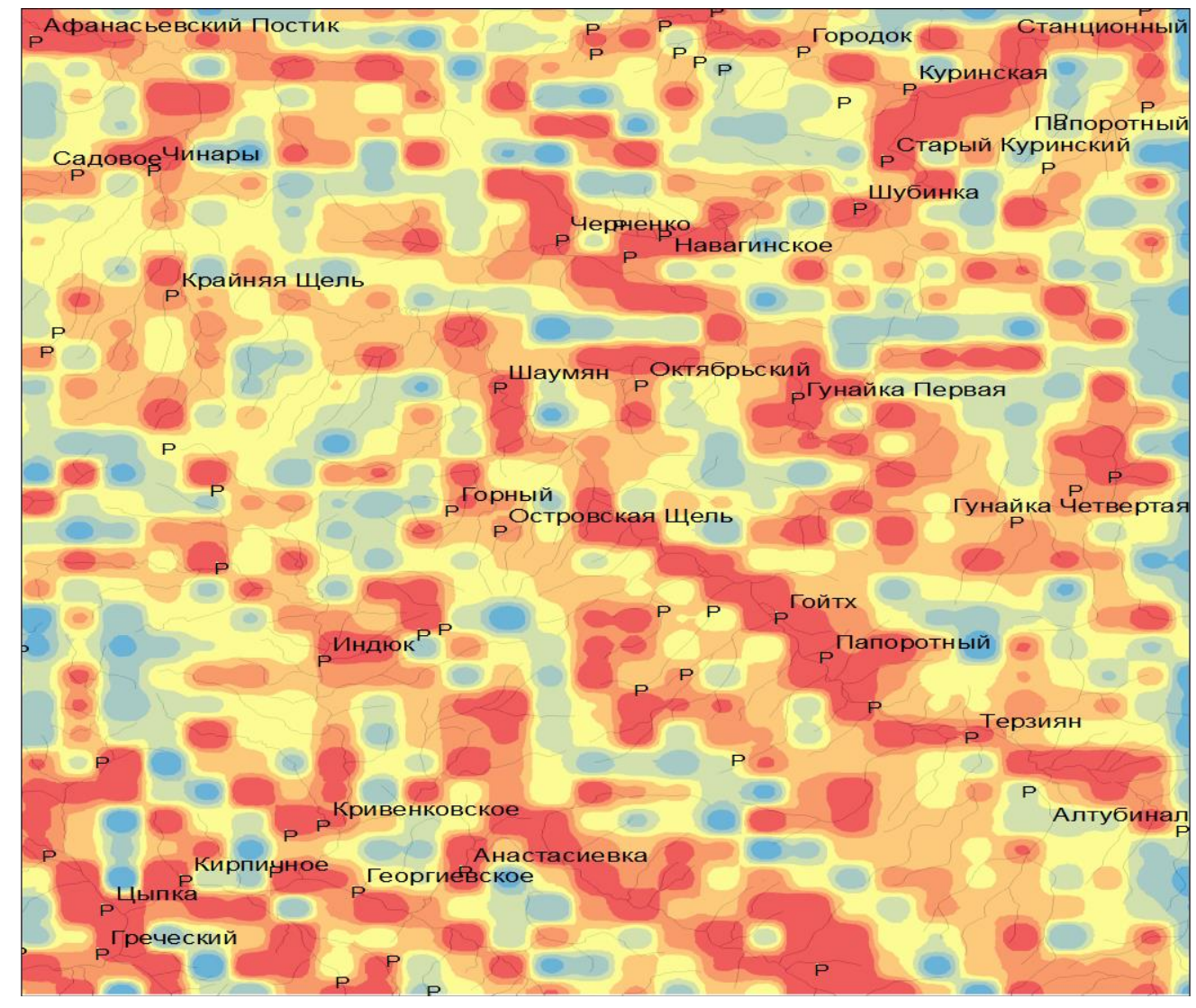

Условные обозначения: 


\section{P Населенные пункты \\ Густота расчленения}

$\mathrm{KM} / \mathrm{KM} 2$

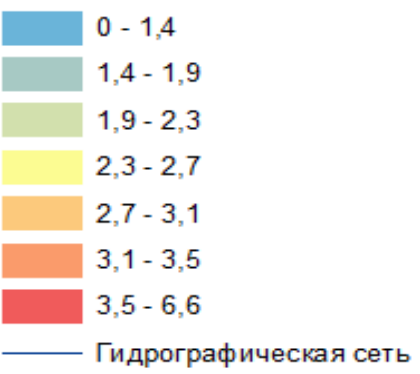

Puc. 1. Карта густоты расчленения территории исследований

Fig. 1. Map of the density of the dissection of the research area

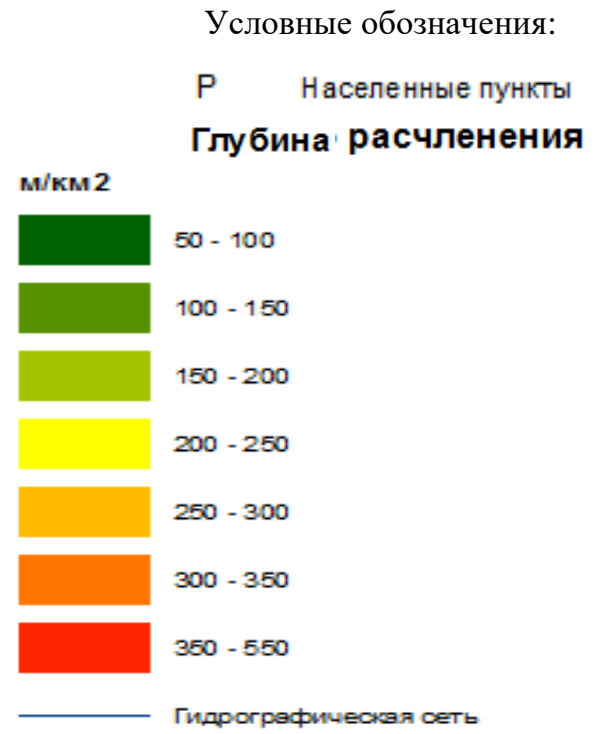

Pис. 2. Карта глубины расчленения территории

Fig. 2. Map of the depth of the erosion division of the territory

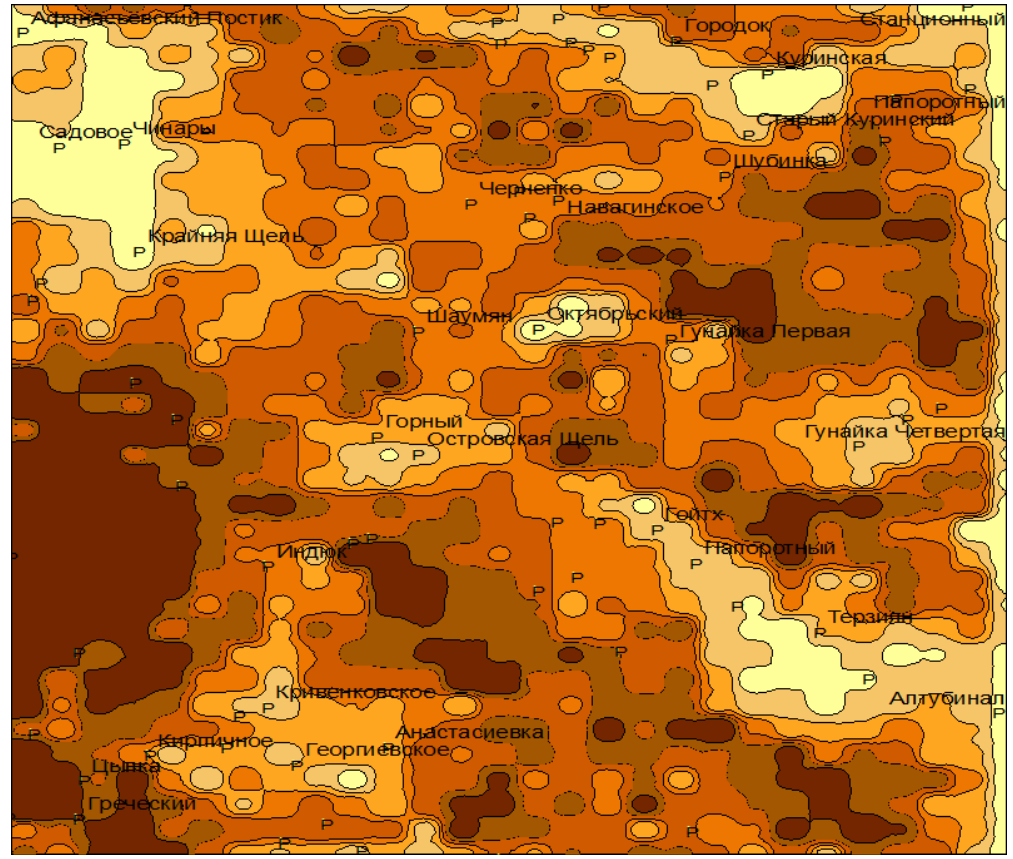

Условные обозначения: 
P Н Населенные пункты

\section{Общее расчленение рельефа} км/км2

\begin{tabular}{|l|l}
\hline & $0-25$ \\
\hline & $25-32$ \\
\hline & $32-37$ \\
\hline & $37-42$ \\
\hline & $42-48$ \\
\hline & $48-55$ \\
\hline & $55-115$ \\
\hline &
\end{tabular}

Рис. 3. Карта общего расчленения рельефа территории Fig. 3. Map of the qeneral dismemberment of the terrain of the territory

Картографическое представление полученной модели приведено на рис. 4. Данные о площадном распределении зон приводятся в таблице 1.

Табл. 1. Площуадная характеристика зон с разной степенью расчленения Table. 1. Areal characteristics of zones with different degrees of separation

\begin{tabular}{|c|c|c|}
\hline $\begin{array}{c}\text { Наимен } \\
\text { ование }\end{array}$ & $\begin{array}{c}\text { Занимаемая } \\
\text { площадь, км }\end{array}$ & $\begin{array}{c}\text { \% от общей } \\
\text { площади зон }\end{array}$ \\
\hline \multicolumn{3}{|c|}{ Зоны максимальной эрозионной расчлененности } \\
\hline 1-я зона & 290,27 & 69,4 \\
\hline 2-я зона & 94,01 & 21,7 \\
\hline 3-я зона & 37,65 & 8,9 \\
\hline
\end{tabular}

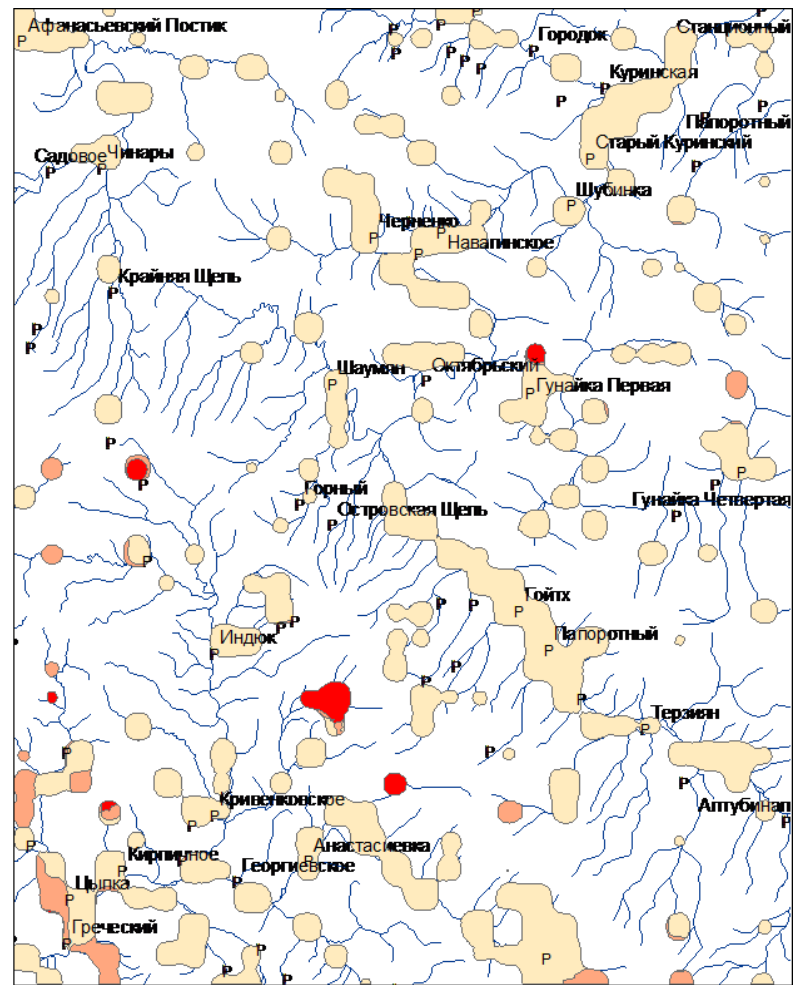


Условные обозначения:

Зоны с высокими значениями густоты расчленения

Зоны с высокими значениями густоты и глубины расчленения

Зоны с высокими значениями густоты, глубины и общего расчленения

Гидрографическая сеть

\section{Населенные пункты}

- с н населением менее 50 тыс. чел.

Pис. 4. Схема зонирования территории по потенциалу рельефа к эрозионным процессам

Fig. 4. The scheme of zoning of the territory according to the potential of relief to erosion processes

Площадь зон максимальной расчлененности составляет 433,24 км², что равно 17,7 \% от общей площади территории исследований. В процентном соотношении к 1 -ой зоне относится 69,4 \%, ко 2 -й зоне - $21,7 \%$, к третьей - $8,9 \%$ от общей пощади территории с высокой расчлененностью.

Построенная карта фактически отражает геоморфологические зоны по вероятности возникновения и характеру развития эрозионных процессов:

1-я зона - паводки возможны при выпадении катастрофических осадков и могут охватывать обширные территории, селевые явления не наблюдаются, происходит вынос преимущественно мелкообломочного материала (песчано-глинистого), реже среднеобломочного (дресвяно-гравийного); активизация оползней возможна на склонах, подрезанных боковой эрозией или автомобильной дорогой при неправильном устройстве дренажа (или его отсутствии);

2-я зона - паводки возможны при выпадении обильных осадков, но будут формироваться в пределах небольших участков, возможно формирование селевых масс, сложенных мелко- и среднеобломочным материалом с включениями крупно-галечникового и щебенчатого материала; возможна активизация оползней. Склоны, лишенные растительности, поражены осыпями и обвалами.

3-я зона - паводки возможны при выпадении обильных осадков, но распространяются в пределах локальных участков, здесь возможно формирование селевых масс, сложенных гравийногалечниковым и крупнообломочным материалом, высокая поражённость территории эрозией, высокая вероятность возникновения оползней, обвалов, осыпей.

Опасные эрозионные процессы будут распространяться последовательно, охватывая зоны от 3 к 1 при увеличении интенсивности и продолжительности осадков. Например, при выпадении обильных кратковременных осадков в пределах водосборного бассейна в зонах 3 категории происходит формирование интенсивного поверхностного стока, характеризующегося высокой скоростью и эрозионной деятельностью, в результате чего происходит изменение конфигурации русла (размыв надпойменных террас, подрезка склонов долин), сопровождающееся переносом обломочного материала. Но при выходе потока в зоны 2 и 1 сила потока снижается. В данных зонах в связи с незначительными углами наклона часть поверхностного стока расходуется на инфильтрационное питание подземных вод, транспирацию растениями, испарение. В случае выпадения катастрофических продолжительных осадков формирование мощного поверхностного стока происходит, в том числе и зонах 2 и 1, что обусловлено превышением прихода воды над фильтрационной способностью грунтов, предела транспирации растений и насыщением воздуха водяным паром (100 \%-ная влажность) при котором испарение прекращается.

Выводы. В результате проведенного пространственно-временного анализа рельефа на территории северного и южного склонов Северо-Западного Кавказа уточнено распределение морфометрических показателей и установлены участки с различными природными предпосылками развития эрозионных процессов. С учетом распределения атмосферных осадков в течение года и их тенденции на увеличение наибольшая вероятность возникновения катастрофических паводков приходится на июнь и ноябрь - январь. Наиболее высокие транспортирующие способности потоков и масса переносимых наносов будет отмечаться в тех зонах, которые по результатам морфометрического анализа рельефа характеризуются высокими значениями показателей расчлененности.

Применение методов ГИС позволило повысить точность и детальность картографирования, которые необходимы для мониторинга и прогнозирования опасных экзогенных процессов на региональном уровне, а также расширило область применения морфометрического анализа. На 
основе серии морфометрических карт возможно создание банка данных для оценки функционального зонирования осваиваемых и перспективных территорий. А карта ранжирования территории по комплексу морфометрических показателей имеет большое прикладное значение и будет полезна, и востребована при планировании строительства новых социально-экономических объектов, при разработке генеральных схем расширения существующих населенных пунктов и проектировании новых, планировании строительства линейных объектов, а также при разработке мероприятий инженерной защиты территорий, зданий и сооружений.

Ссылка на данную статью: Бондаренко Н.А., Иванусь И.В., Куропаткина Т.Н., Золотарев А.А. (2020). Оценка рельефа как фактора развития эрозионных процессов на основе ГИСтехнологий. Материалы Международной практической интернет-конференции «Актуальные проблемы науки» [Challenges of Science]. Выпуск III, стр. 137-144. https://doi.org/10.31643/2020.019

\section{Литературы}

Бондаренко, Н.А., Любимова, Т.В., Стогний, В.В. (2020). Интегральная оценка потенциальных геологических рисков Краснодарского края. Материалы Международной конференции "ИнтерКарто. ИнтерГИС" (24 и 25 сентября 2020, г. Пятигорск). Том 26, ч. 2. Географические информационные системы и технологии. с.189-200. https://doi.org/10.35595/2414-9179-2020-2-26-189-200

Буряк, Ж.А. (2014). Совершенствование подходов к оценке эрозионной опасности агроландшафтов с использованием ГИСтехнологий. Научные ведомости. Серия естественные науки. 23 (194). Вып. 29. $2014 . \quad$ С. $140-146$. http://elibrary.ru/item.asp?id=22924227

Васильев, М.П., Петерс, А.А. (2017). Оценка погодноклиматических рисков для сектора экономики и социальной сферы на региональном уровне (на примере Краснодарского края). Труды главной геофизической обсерватории им. А.И. Воейкова. №586. Главная геофизическая обсерватория им. А.И. Воейкова. Санкт-Петербург. 2017. С. 34-64. https://elibrary.ru/item.asp?id=30628123

Ермолаев, О.П., Мальцев, К.А., Мухарамова, С.С. (2019). Геоинформационная система «Бассейны малых рек России» в решении задач по оценке интенсивности эрозии. Закономерности проявления эрозионных и русловых процессов в различных природных условиях. Материалы V Bсеросс. научной конф. с междунар. (г. Москва, 3-6 сентября 2019 г.). М.: ЛЕНАНД. 2019. С. 201-202. https://repository.kpfu.ru/?p_id=212894

Золотарев, А.А. (2018). Моделирование эрозионной деятельности водотоков на примере горных районов Краснодарского края. Геология в развивающемся мире. Сборник науч. трудов по материалам XI Межд. науч.-практ. Конф. Студентов, аспирантов и молодых ученых: в 3-х томах. Пермский государственный национально-исследовательский университет. 2018. C. 35-38. https://elibrary.ru/item.asp?id=36572568

Ткаченко, Ю.Ю. (2015). Глобальное изменение климата как фактор, оказывающий влияние на характер экзогенных процессов на территории Краснодарского края. Инженерная геология Северо-Западного Кавказа и Предкавказья: современное состояние и основные задачи. Сборник науч. трудов. ISBN 978-5-93491-725-9. Краснодар: ПросвещениеЮг. 2015. С. 39-43.

\section{References}

Bondarenko N.A., Lyubimova T.V., Stogny V.V. Integrated assessment of potential geological risks in the Krasnodar region InterCarto. InterGIS. GI support of sustainable development of territories: Proceedings of the International conference. Moscow: Moscow University Press, 2020. V. 26. Part 2. P. 189-200. DOI: 10.35595/2414-9179-2020-2-26-189-200 (In Russian)

Buryak, Zh.A. (2014). Improving approaches to assessing the erosion hazard of agricultural landscapes using GIS technologies. Scientific reports. Natural Sciences series. 23 (194). Issue 29. 2014. pp. 140-146. (In Russian). http://elibrary.ru/item.asp?id=22924227

Vasiliev, M.P., Peters, A.A. (2017). Assessment of weather and climate risks for the economy and social sector at the regional level (on the example of the Krasnodar territory). Proceedings of the Voeykov main geophysical Observatory. №586. Voeykov main geophysical Observatory. Saint Petersburg. 2017. pp. 34-64. (In Russian). https://elibrary.ru/item.asp?id=30628123

Ermolaev, O.P., Maltsev, K.A., Mukharamova, S.S. (2019). Geoinformation system "basins of small rivers of Russia" in solving problems of assessing the intensity of erosion. Regularities of erosion and riverbed processes in various natural conditions. Materials of the V all-Russian scientific conference with international (Moscow, 3-6 September 2019). M.: LENAND. 2019. Pp. 201-202. (In Russian). https://repository.kpfu.ru/?p_id=212894

Zolotarev, A.A. (2018). Modeling of erosion activity of watercourses on the example of mountainous regions of the Krasnodar territory. Geology in the developing world. Collection of scientific works based on the materials of the XI Century. scientificpractical. Conf. Students, postgraduates and young scientists: in 3 volumes. Perm state national research University. 2018. Pp. 35-38. (In Russian). https://elibrary.ru/item.asp?id=36572568

Tkachenko, Yu.Yu. (2015). Global climate change as a factor influencing the nature of exogenous processes in the Krasnodar territory. Engineering Geology of the North-West Caucasus and Ciscaucasia: current state and main tasks. Collection of scientific works. ISBN 978-5-93491-725-9. Krasnodar: Prosveshchenie-Yug, 2015, Pp. 39-43. (In Russian). 